\title{
Social network sites and methodological practices
}

\author{
Heba Sayed", George Dafoulas and Noha Saleeb \\ MiddleSex University, London, England \\ (C)2018 ACCENTS
}

\begin{abstract}
The internet and its social applications have imposed themselves as the essential tools in people's everyday life. Social network sites (SNS) researches hence become a lucrative field of study among diverse scholars who have developed and published several studies throughout the past ten years. Drawing on the methodological research work accomplished so far to study SNS and its impact on people and communities around the world, this paper focuses on the type of methodologies practiced in most researches addressing SNS global phenomenon. Hence, the paper queries are: 1) what are the publications trends normally used in publishing SNS literature? 2) What are the research methods commonly practiced in literature? 3) Suggestions for various other methodological options to employ. This paper is grounded on studying an array of 112 research papers published from 2006 to 2016 where articles were identified through a systematic process. Articles followed a four staged process where they were reviewed, analysed, and coded through a qualitative content analysis approach. Findings show the publications in all disciplines are discussing SNS from one angle or another. Secondly, the most used research method by researchers and scholars across various disciplines is quantitative tools mostly online surveys followed with ethnography through observation of content analysis of sites. The mixed methods methodology represents only $9 \%$ of the investigated sample. Further, not much research is accomplished about the Middle East region as the analysis presents only 15\% mainly focusing on SNS's usage pattern rather than arising indepth investigation of changes in people's life. Recommendations to obtain offline genuine human preferences and opinions gathered through face to face focus group and interviews in addition to online behaviours trending for more informative results and predications. Likewise, for the Middle East region, need to investigate acutely SNS's impact on changing people pattern of behaviour and cultural structure.
\end{abstract}

\section{Keywords}

Social networks sites, Social media research, Methodology, Mixed methods.

\section{Introduction}

This paper presents a descriptive analysis of the methodological approaches practiced in literature addressing SNS. Illustration trends of qualitative and quantitative research methods employed by researchers accompanied with analysis of those methods as well as emphasis of mixed approaches.

Mixed methods research approaches "in which the researcher gathers both quantitative (closed-ended) and qualitative (open-ended) data, integrates the two and then draws interpretations based on the combined strengths of both sets of data to understand research problems" Creswell et al. 2014 [1] do provide valuable results in analyzing the impact of SNS on people's life and shaping their cultures.

*Author for correspondence
The potential value of examining trends in the use of qualitative research approaches (e.g., interview, focus group, and qualitative content analysis) lies in uncovering how researchers design studies to gain insights into how and why people engage with social media as well as the meaning that is attached to experiences with social media [2]. For example, Gomes et al. 2014[3] successfully employed multiple tools such as interviews and focus group followed by case study of a prototype social tool to test the adoption of senior users to SNS. In another study, Andriole et al. 2010 [4] combined interviews, observation of applying SNS tools, and survey datacollection methods in investigating the impact of Web 2.0 tools on USA industrial companies.

Social media research is a relatively new field of study that has emerged in conjunction with the development of social media technologies and the upsurge in their use [5]. As per Snelson et al. 2016 [2], prior literature reviews from [6-8] have included discussions of trends in research approaches but have 
provided a more global classification of general trends. Williams et al. 2013[9] thus trends in the selection of research design, data collection techniques, and analytic approaches are not well known.

Hence, the objectives guiding this systematic literature review paper are to uncover the periodicals trends commonly publishing about SNS literature; the research methods frequently practiced; and last but not the least, recommendations and suggestions for various other methodological options to employ.

\section{Literature review}

It is important to be online, i.e. 'If you are not online, you don't exist' as claimed by Snell (2009) [10]. The World Wide Web (WWW) is a subclass of the internet comprised of web pages that are created using hyper-text mark-up language (HTML) and are transmitted through hardware devices such as computers, tablets, mobiles, excreta via hypertext transfer protocol (HTTP) over fibre optics submarine cable systems fastening the earth planet. Over time those web pages have been transformed from mere one way information conduit to interactive content platforms thanks to the development of Web 2.0 technology. The greatest phenomena of this age are social networking, followed by self-broadcasting and collaborative content creation. SNSs are web pages with social features. Social Network Sites also known as online social networks is a web-based services that allow individuals to (1) construct a public or semipublic profile with a bounded system, (2) articulate a list of their users with whom they share a connection, (3) view and traverse their list of connection and those made by others within a system[11]. Kaplan et al. 2010 [12] defined social media as a group of internet-based applications that build on the ideological and technological foundations of Web 2.0, and that allow the creation and exchange of user generated content. The two important criteria for success and widespread of SNSs among internet population are content sharing and sociability [13]. SNS can be categorized into three main categories based on users' objective: (1) personal socialization oriented e.g. Facebook and Google Plus, Twitter (2) information search oriented e.g. Amazon owned Goodreads (3) professional network oriented e.g. LinkedIn, Visible Path, Xing (formerly openBC). One of the main differentiator of SNS from public computer-mediated communication (CMC) such as Usenet and other public forums is that SNS rotates around people networks instead of topic which is the focus of online forums [14]. By 2019, it is estimated that there will be around 2.77 billion social network users around the globe up from 2.46 billion in 2017 [15].

All previous accomplished researches have proven that SNS contributes with an impact on societies, cultural attitudes and behavioral change as well as on communities' identity across nations. Some researchers have focused on a specific social media platform such as the leader of social networks i.e. Facebook [16-21], Twitter [22]; or YouTube [23]. In addition to others that have focused on issues or subjects related to social networks sites such as health-care professionals [7], tourism and hospitality [24], or prediction of real-world events [25], privacy concerns [26-28], education and learning [29-31].

Thus throughout the past 15 years, there are a lot of efforts exerted by researchers and scholars in studying and understanding social networks in its kernel as well as how it affects people's culture and all aspects of life. A lot of papers, surveys and studies tackled SNS in term of usage, features, kinds, and impacts as well as the development of its supporting infrastructure technologies; however little was done in investigating the research design tool selected to fulfil those endeavour's aims to understand social networks. Therefore, this literature analysis paper will primarily produce a brief overview of the publications of selected scholarly activities done in the area of studying SNS. Then a detailed process for scrutinizing the methodological approaches utilized respectively in literature.

\section{Methodology}

Creswell (2002)[32] noted that quantitative research is the process of collecting, analysing, interpreting, and writing the results of a study, while qualitative research is the approach to data collection, analysis, and report writing differing from the traditional, quantitative approaches. The research design refers to the overall strategy that researchers choose to integrate the different components of the study in a coherent and logical way, thereby, ensuring effective address of the research problem and its objectives; it constitutes the blueprint for the collection, measurement, and analysis of data [33]. According to Creswell (2002) [32], researchers resort to combined methods so as to accommodate both research traditions. The goal for researchers using the mixed methods approach is to draw from the strengths and minimize the weaknesses of the quantitative and qualitative research approaches [34]. A weakness of most previous research, however, is that it has been 
qualitative or mixed methods [35] but reported in a predominantly qualitative fashion [36] and hence forms conjectures rather than presenting testable evidence [37]. This is not a criticism to qualitative method as it's an ultimate method to cater for studying a subject directly dealing with human beings e.g. SNS; nevertheless administering it with quantitative methods are strongly recommended to test and generalize findings which is the benefit of mixed methods.

The most considerable barrier to social media usage is the lack of a versatile methodology for selecting, collecting, processing and scrutinizing contextual information obtained from social media sites [2]. However, several software companies have developed proprietary text mining systems for data visualization [38], and researchers have developed expert systems for sentiment analysis [39-40] of qualitative data.

This paper follows an assimilating descriptive approach in investigating the literature's methodologies which "attempts to summarize the contents of multiple studies and minimizes any interpretation on the part of the reviewer" [41]. The unit of analysis is articles and/or papers from publications tackling the current phenomenon of SNS to investigate the research methods utilized whether it's qualitative, quantitative or mixed methods. Articles of search were confined to papers covering the period from 2006-2016. The reason for this time selection is based on the novel nature of this field of study as SNSs have noticeably started almost around 2004 by Facebook, You Tube 2005, Twitter 2006, Pinterest 2010, Google+ 2011. Facebook research was published as early as 2005 [21]. Williams et al. 2013 [9] selected 2007 as a starting point for their literature review of Twitter and micro-blogging research because that is when the first papers began to appear. 2016 was the concluding date of the analysis as not much articles were found during the first half of 2017, so author prefer to confine search to a full 10 years one.

Reviews of journals papers or articles were selected through a systematic analysis process based on the topic of SNS through keywords, time duration earlier specified and the implementation of a research methodology. Figure 1 shows the phases of literature review analysis. Selection and analysis process follows four phases as follows:

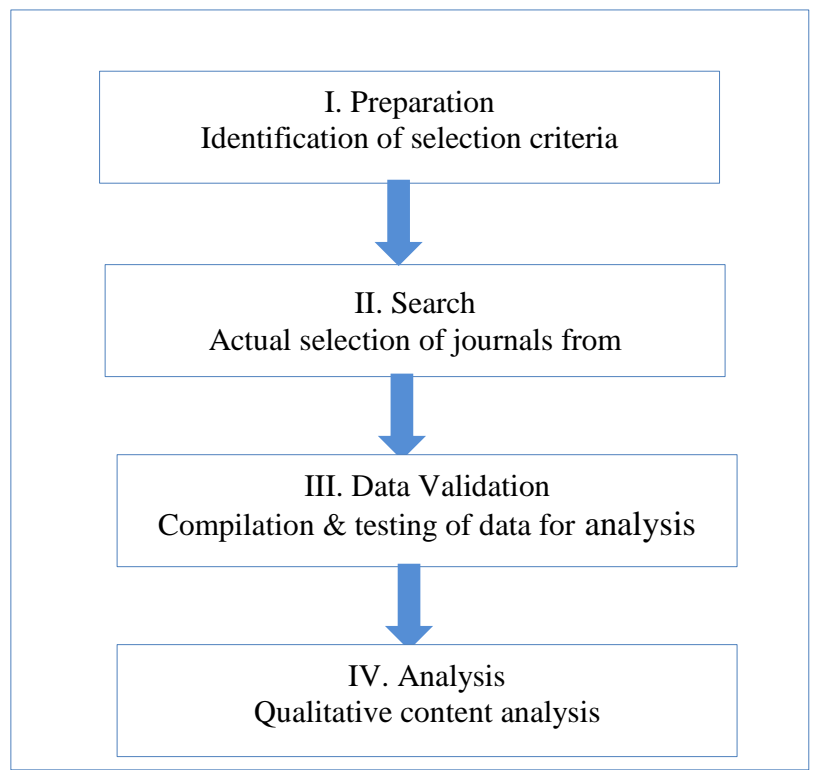

Figure 1 Phases of literature review analysis

Phase I: Preparation

This stage starts with setting criteria for selection of targeted publications. This study combines platform and time specific as well as general phrases search in order to reach multiple arrays of papers for exploring the methodologies applied in selected topic under investigation.

a. The investigated publications address SNS, so the keywords identified for the search are general terms like social networks sites, social networking, social media, SNA or specific sites like Facebook, YouTube and Twitter.

b. The investigated publications are within the specified period from 2006 through 2016.

c. The investigated bibliographic entries available in databases.

d. The investigated publications apply a research methodology whether qualitative, quantitative or mixed methods approach.

e. The investigated publications have a full copy in English language.

Phase II: Search

The search was carried throughout a year during 2017 for articles or papers fulfilling the above five mentioned criteria in Preparation phase. This analysis paper is based on methodological trends in multidisciplinary repository such as academic Search of MiddleSex and AUC University, Web of Science, and Google Scholar including databases such as ACM digital library, Wiley Online Library, IEEE explore digital library, Research Gate, SAGE 
journals, etc. Google Scholar was included as one of the databases searched due to its broad reach across interdisciplinary academic scholarship indexed on the internet and its use in prior literature review studies [16, 22, 25, 9, 21]. Since Google scholar presents a lot of result that is unrelated to the main search field which is considered a limitation that required using other accredited search engines such as Web of Science and academic online libraries as those earlier mentioned for an effective time saving and comprehensive results.

\section{Phase III: Data Validation}

Abstracts and full journals or papers were read to determine their compliance with earlier set criteria. A total of 112 studies from an array of search results of 150 scholarships met the specified criteria in 84 multidisciplinary publications. Data validation feature available in Microsoft Excel permits to check for incorrect or repeated entries by using auditing toolbar so this help to remove duplicate entries; determine the numeric values that can be entered in a cell which supports the selection of pre-determined timespan; restricting the entries allowed in a cell through creating research methods design checkbox with none as an option for exclusion in analysis phase.

Phase IV: Analysis

The analysis is a qualitative content investigation, based on Schreier's (2012) [42] approach to arrange and comprehend the literature. As per Schreier (2012) [42], it's a method of systematically describing the meaning of data through assigning a successive part of the material to the category of coding frames; which is concept driven defined in advance and data driven derived from data during coding. This analysis was implemented by a single researcher so multiple rounds were done to crosscheck and validate data results. The process involves a) extracting a full text copy of the articles or studies from each repository source; b) developing of bibliographic information linked to each article; c) followed by creating a classified table with the required data such as a spread sheet for working analysis. Tags were added to each article to indicate relevance to investigated topic and the utilization of research approaches. Hence required data was exported to excel sheet (Microsoft, 2010) for tabulation of data and second round of coding based on research query. In Excel sheet, the pivot tables were created for the development of meanings from data and illustrative graphs. As data is adding on, for any inconsistencies noticed in summation or trending an overall review is done for rectification of these differences.

\section{Findings and discussion}

The results of this analytical study will be systematically structured from general to specific. Out of 150 surveyed articles from 84 publications, 112 articles or studies were selected with respect to pre-defined criteria. Then full text versions of those articles were read where data was extracted and tabulated for analysis and illustration. The results are presented in two folds; once related to publications trends and the other related to methodological methods practiced.

\subsection{Publications analysis}

The 84 publications are multi-disciplinary covering most aspects of life e.g. IT, Computer Science, Business, Education, Politics, Psychology, Sociology and Economy, etc. This emphasizes the diffusing impact of SNS in all aspects of life. To follow is a list of the publications and their impact factor respectively. Table 1 shows the list of journals with two or more SNS studies.

Table 1 List of journals with two or more SNS studies

\begin{tabular}{|c|c|c|}
\hline Journals titles & $\begin{array}{l}\text { \#Of searched } \\
\text { articles }\end{array}$ & $\begin{array}{l}\text { Impact factor } \\
2016\end{array}$ \\
\hline $\begin{array}{l}\text { Journal of Computer- } \\
\text { Mediated } \\
\text { Communication }\end{array}$ & 7 & 4.113 \\
\hline $\begin{array}{l}\text { Computers in Human } \\
\text { Behavior }\end{array}$ & 5 & 3.435 \\
\hline Information Sciences & 2 & 4.95 \\
\hline $\begin{array}{lr}\text { Electronic } & \text { Commerce } \\
\text { Research } & \text { and } \\
\text { Applications } & \end{array}$ & 2 & 3.56 \\
\hline PLoS ONE & 2 & 3.54 \\
\hline $\begin{array}{l}\text { Technological } \\
\text { Forecasting \& Social } \\
\text { Change }\end{array}$ & 2 & 3.226 \\
\hline $\begin{array}{l}\text { Cyber Psychology and } \\
\text { Behavior }\end{array}$ & 2 & 3.22 \\
\hline $\begin{array}{l}\text { Educational } \\
\text { Technology \& Society }\end{array}$ & 2 & 1.584 \\
\hline $\begin{array}{l}\text { Journal of Applied } \\
\text { Developmental } \\
\text { Psychology }\end{array}$ & 2 & 2.146 \\
\hline $\begin{array}{l}\text { Journal of the } \\
\text { Association } \\
\text { Information for } \\
\text { and Technology }\end{array}$ & 3 & 2.322 \\
\hline $\begin{array}{l}\text { Social Science } \\
\text { Computer Review }\end{array}$ & 2 & 1.90 \\
\hline Business Horizons & 2 & 1.84 \\
\hline
\end{tabular}




\begin{tabular}{lll}
\hline Journals titles & $\begin{array}{l}\text { \#Of searched } \\
\text { articles }\end{array}$ & $\begin{array}{l}\text { Impact factor } \\
\mathbf{2 0 1 6}\end{array}$ \\
\hline $\begin{array}{l}\text { International Journal } \\
\text { of human computer }\end{array}$ & 2 & 4.667 \\
Interaction & \\
\hline Library Hi Tech & 2 & 0.759 \\
\hline $\begin{array}{l}\text { AIS Transactions on } \\
\text { Human-Computer }\end{array}$ & 2 & 1.086 \\
Interaction & 2 & \\
\hline ACM & 2 & 1.293 \\
\hline Computer Networks & 2.93 \\
\hline
\end{tabular}

Seventeen Out of the 84 publications contributes with the highest number of articles under investigation which are "The Journal of Computer-Mediated Communication" comprising the highest number of papers or studies reviewed followed by "Computers in Human Behavior" then "Information Science" and "Electronic Commerce Research and Applications", etc. Those journals possess high score of Impact Factor respectively. $69 \%$ of the articles discuss SNS history, features, and technical infrastructure as well as its impact in general term. With $31 \%$ social network site specific articles mainly Facebook, the lion share in subscriber numbers annually, contributes with $15 \%$ of the articles, followed by twitter then LinkedIn and My Space in earlier years of study.

To follow are illustrations of the count of articles in publications tackling SNS methodologically across time as well as its geographical coverage. Figure 2 shows the count of SNS articles in publications. Figure 3 shows the Count of geographical coverage of articles.

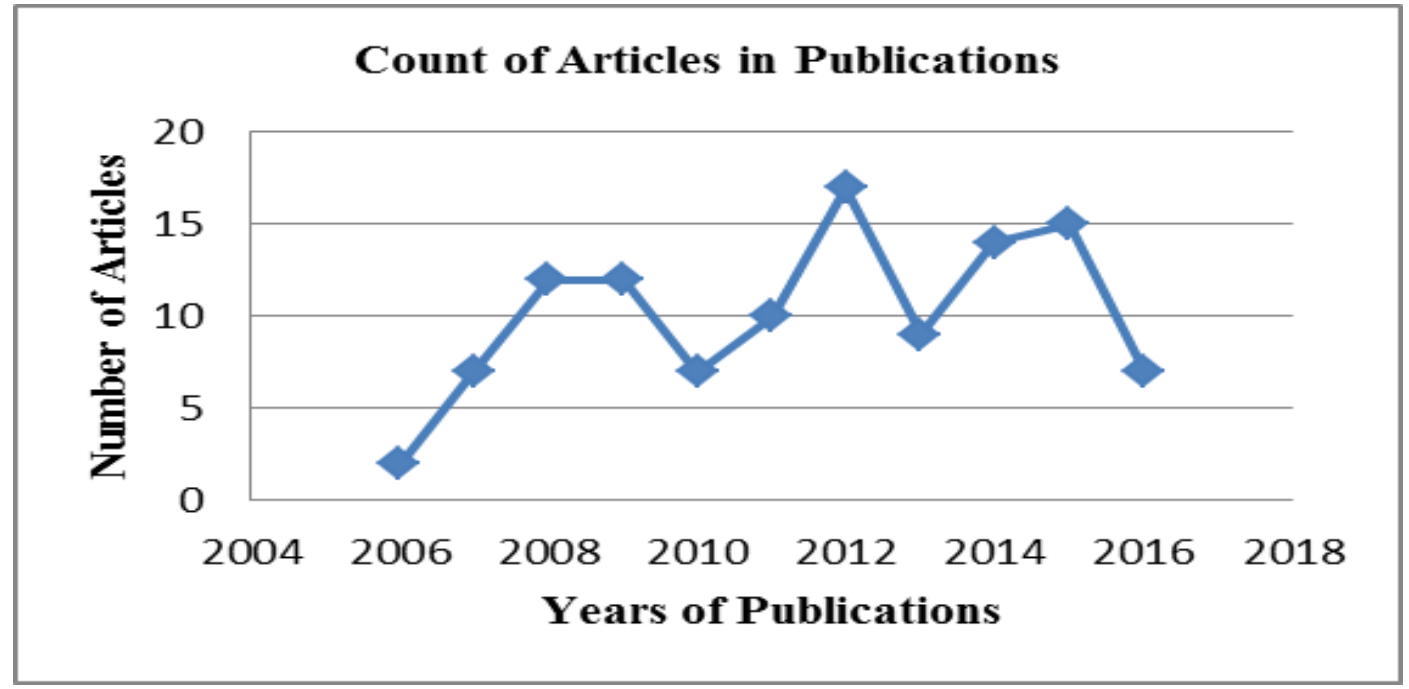

Figure 2 Count of SNS articles in publications

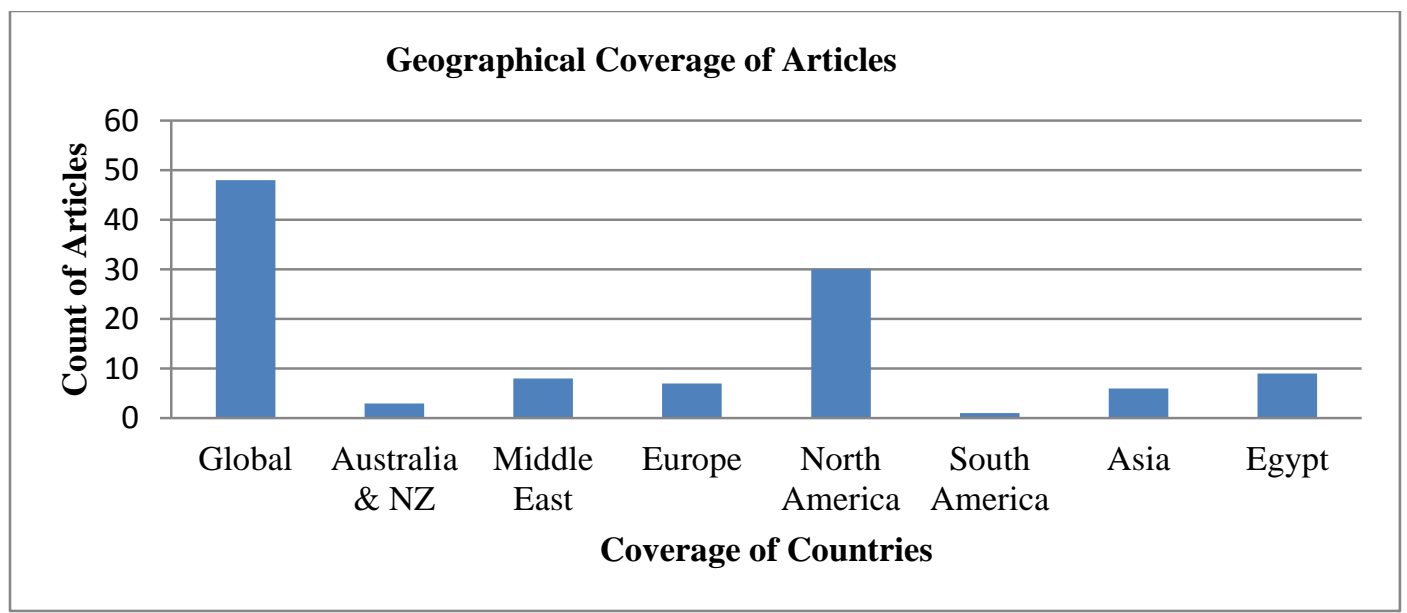

Figure 3 Count of geographical coverage of articles 
The chronological graph shows that scholars' interest in SNS phenomenon is growing over time reaching the peak number of articles by 2012 within the surveyed ten years duration amounting to $15 \%$ of total studies. This can be explained partial due to the global development, spread and emergence of SNS such as Facebook, You Tube, twitter, Google+ respectively after almost 5 years from inception. On the other hand the occurrence of major global events such as Apple released Iphone by 2007, the boom in internet development especially broadband by 2008 and Google had processed one trillion unique URL (Uniform Resource Locator) stands for a web address, Global economic downturn by 2009 where people attempted to find alternative online job source, Haiti earthquake 2010 and Middle East Arab Spring revolutions during 2011/12 where SNS was a global catalyst for communication and dissemination of information among societies. Then, interest in SNS studies increased again by 2014 and 2015 amounting to $13 \%$. Concerning the geographical coverage chart, majority of the articles are generic across the globe tackling SNS features, usage pattern, technical setup and impact on various aspect of life with limited ratios about specific countries. North America represented by USA has the lion share of country specific studies amounting to $26 \%$ followed by Middle East and Egypt totalling to $15 \%$. It's worth mentioning that accomplished articles about the Middle East focus on SNS's usage density, trends and its political impact rather than exploring arising issues related to SNS such privacy, education, health, citizenship, etc.

\subsection{Methodological analysis}

The second objective of this paper is to analyse the methodological approaches practiced by researchers and scholars in studying SNS. Analysis indicates that the most practiced design methodology is Survey or questionnaire reaching 32\% which varies from tradition manual questionnaire to the mostly used online questionnaire. Then second in ranking design tool is Observation and content analysis of data extracted from SNS records for measuring behaviours of online users and trending predications which amounts for $22 \%$. Next in use Case Study research technique amounting to $19 \%$ which sometimes combines Interviews and Observation of data. Followed by Illustrative data amounts for a good portion within scholars literature reviews where description of earlier work done coupled with explanation of SNS nature and its impact on communities exists with $15 \%$ of reviewed Journals.

At a decreasing rank comes Interviews at $7 \%$ of total reviewed articles. It is noticed that Interviews are rarely a standalone research technique for studying SNS; in most cases it is coupled with Observation content analysis of extracted data or following a Focus Group or within a Case study. Last but not the least is Experiment or Quasi Experiment which is not much popular in practice for studying SNS with 5\% ratio practiced by highly technical background scholars approaching SNS studies through examining prototype such as pilot project application for senior use of SNS tested by Gomes et al. 2014 [3] and Benford's Law Applies to Online Social Networks by Golbeck (2015) [43].

Further, analysis revealed that Mixed Methods technique was used with a limited ratio which is $9 \%$ mainly in combining Observation Content analysis with Interviews, Case study and Survey. The following table provides a quantitative summary of articles analysis with respect to data collection techniques and analytical approaches. Table 2 shows the matrix of methodological approaches in social network sites research. Figure 4 shows the ratios of methodological research tools in SNS Research.

Table 2 Matrix of methodological approaches in social network sites research

\begin{tabular}{|c|c|c|c|c|c|}
\hline \multicolumn{6}{|c|}{ SNS Research methodological designs } \\
\hline \multicolumn{2}{|r|}{ Case study } & Ethnography & $\begin{array}{l}\text { Grounded } \\
\text { theory }\end{array}$ & Quantitative & Mixed methods \\
\hline $\begin{array}{l}\text { Number of } \\
\text { Studies }\end{array}$ & 21 & 24 & 24 & 41 & 12 \\
\hline \multicolumn{6}{|c|}{ A. Data collection techniques } \\
\hline Observation & $\mathrm{X}$ & $\mathrm{X}$ & $\mathrm{X}$ & & $\mathrm{X}$ \\
\hline Focus Group & $\mathrm{X}$ & & $X$ & & $X$ \\
\hline Interview & $\mathrm{X}$ & $\mathrm{X}$ & $\mathrm{X}$ & & $X$ \\
\hline Surveys & & & & $\mathrm{X}$ & $\mathrm{X}$ \\
\hline Illustration Da & & & $\mathrm{X}$ & & $\mathrm{X}$ \\
\hline Experiment & & & & $\mathrm{X}$ & $\mathrm{X}$ \\
\hline
\end{tabular}




\begin{tabular}{|c|c|c|c|c|c|}
\hline \multicolumn{6}{|c|}{ SNS Research methodological designs } \\
\hline \multicolumn{2}{|c|}{ Case study } & Ethnography & $\begin{array}{l}\text { Grounded } \\
\text { theory }\end{array}$ & Quantitative & Mixed methods \\
\hline \multicolumn{6}{|c|}{ B. Analytical Approaches } \\
\hline Coding & $\mathrm{X}$ & $\mathrm{X}$ & $\mathrm{X}$ & & $\mathrm{X}$ \\
\hline Content Analysis & $\mathrm{X}$ & $\mathrm{X}$ & $\mathrm{X}$ & & $\mathrm{X}$ \\
\hline Discourse Analysis & $\mathrm{X}$ & $\mathrm{X}$ & & & \\
\hline $\begin{array}{l}\text { Explorative Usabil } \\
\text { tests }\end{array}$ & & & & $\mathrm{X}$ & \\
\hline Statistical analysis & & & & $\mathrm{X}$ & $\mathrm{X}$ \\
\hline
\end{tabular}

Note: * Illustrative data stands for large among of descriptive data about social networks sites

SNS Research Methods Applied

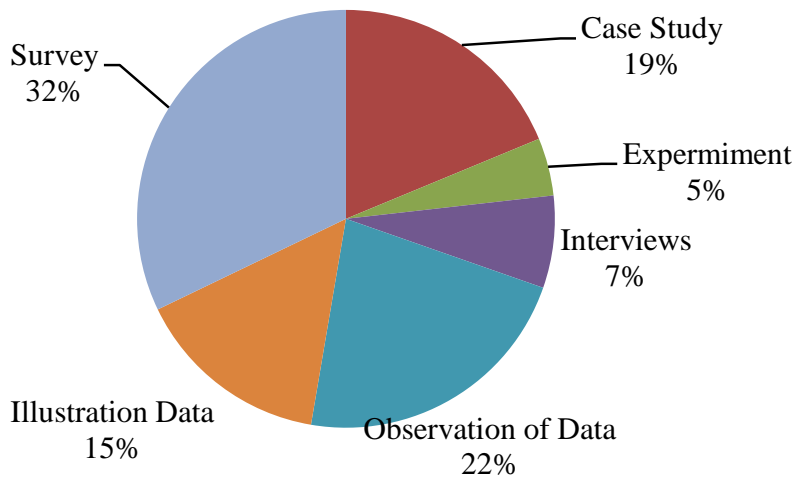

Figure 4 Ratios of methodological research tools in SNS research

According to Mathers et al. 2007 [44], the selection of the appropriate survey design depends upon a number of factors such as access to potential participants/respondents, the literacy level of respondents, the subject matter, the motivation of the respondents and resources. Studies of online populations have led to an increase in the use of online surveys, presenting scholars with new challenges in terms of applying traditional survey research methods to the study of online behaviour and internet use [45]. Companies like Survey Monkey and super Surveys are in the business of hosting online surveys for a limited time. Thus the adaption of surveys is massive due to the availability of supportive tools and software whether in data collection or analysis phase.

Further from the above illustration, it is worth mentioning that Focus Group is the least used technique among all. Assumption is that due to the nature of SNS being an online communication and socialization tool, then most researchers rely on extracting people's preferences and behavioural trends through observation and analysis of online data through software extraction tools rather than meeting those people in reality. One of the factors is saving time needed to arrange and conduct a focus group; other is the plenty of records that can be extracted using latest software techniques rather than the limited data resulting from conducting a 7-10 focus group participants per session. However, focus group can provide in depth information with option of further elaboration on people's online behaviours and preferences more than the static manipulation of data also it improves data sampling and validation.

Concerning analysis techniques, the technique depends on the practiced collection method. So for quantitative methods such as surveys, researchers commonly use statistical analysis such as SPSS, structural equation modelling (SEM) or exploratory analysis (EFA) or confirmatory factor analysis (CFA). Rarely researchers use combination of more than one analytical tool. On the other hand for qualitative techniques such as observation, case studies and Interviews, NVIVO software packages and content analysis is mainly practiced by scholars through coding of observed data followed by content analysis and graphical illustration of data. As for 
illustration data, correlation and comparisons are used to contrast different views, models, theories, etc. Last but not the least for experiment exploratory usability test is considered.

Accordingly based on those quantitative and qualitative techniques for investigating SNS phenomenon, epitomized mainly in surveys and observation content analysis, Social Network Analysis (SNA) discipline was created which studies the relationship between nodes (people) and ties (links or relationships) within a live network across human beings. SNA is a methodology to map, quantify and analyse the patterns of connection between actors, be these individuals, community groups, company boards or government departments [46].

So in answering the third objective of this paper, since SNS is an across the board human related subject matter then all spectrum of research methods can be used depending on the angle of study and the researcher's academic background. However, it will be effective to combine human offline research methods e.g. focus group and interviews with observation content analysis and online surveys for acquiring a face to face real users interaction and observing people themselves in addition to their online recorded data.

\section{Conclusion}

This analysis reveals the growing scholarship's interest in studying social network sites' trends and impact. Researches focusing on SNS must address human's communicational actions and behaviours in engaging with those interactive applications that call examiner to open wide his/her eyes for observation, surveillance, reflection, and two-ways discussions for the collection of data from community thus enabling adequate analysis and conclusions formulation. This paper presents a descriptive qualitative content analysis of 112 SNS related articles and papers within 84 publications. The process of analysis of research methodologies in literature was methodical following a general to specific scenario. The process comprises of four phases: Preparation, Search, Data validation and Analysis. In the final phase of the investigation, the investigator ensures that the results obtained in Phase 3 are interpretable, specifically with regard to the goal and scope defined earlier. The investigator summarizes the findings, identifies the managerial and practical implications of the findings, and acknowledges the limitations of the study.
Hence, Survey or questionnaire is the most popular used research technique by scholar in studying SNS with $32 \%$. Following is Observation content analysis extracted from SNS archival for measuring behaviours of online users and trending predications which amounts for $22 \%$. Mixed Methods techniques were used with a marginal ratio amounting to $9 \%$; mainly in practicing Observation data analysis within Case Studies or applying Observation before Interviews and surveys. However, mixed methods research approaches involving network analysis are emerging and evolving as researchers grapple with the challenges and benefits for studies involving social networks [47]. SNS Studies about the Middle East contributes with only $15 \%$ and mainly focusing about statistical analysis of consumption. Many scholars have analysed SNS but little was mentioned about the how to analyse it. So, this paper contributes to the knowledge base in tackling a specific area which is the use of research methodology in SNS investigation through examining researchers' choice of design trends, data collection and analysis techniques rather than approaching SNS itself. The analysis reveals the importance to combine offline with online research tools for yielding richer findings. Future work in this area can be done in carrying in-depth analysis of alternative mixed methods methodologies which was not cover in this article.

\section{Acknowledgment}

None.

\section{Conflicts of interest}

The authors have no conflicts of interest to declare.

\section{References}

[1] Creswell JW. A concise introduction to mixed methods research. Sage Publications; 2014.

[2] Snelson CL. Qualitative and mixed methods social media research: a review of the literature. International Journal of Qualitative Methods. 2016; 15(1):1-15.

[3] Gomes G, Duarte C, Coelho J, Matos E. Designing a facebook interface for senior users. The Scientific World Journal. 2014:1-8.

[4] Andriole SJ. Business impact of Web 2.0 technologies. Communications of the ACM. 2010; 53(12):67-79.

[5] Duggan M, Ellison NB, Lampe C, Lenhart A, Madden M. Social media update 2014. Pew Research Center, 2015.

[6] Best P, Manktelow R, Taylor B. Online communication, social media and adolescent wellbeing: a systematic narrative review. Children and Youth Services Review. 2014; 41:27-36. 
[7] Hamm MP, Chisholm A, Shulhan J, Milne A, Scott $\mathrm{SD}$, Klassen TP, et al. Social media use by health care professionals and trainees: a scoping review. Academic Medicine. 2013; 88(9):1376-83.

[8] Jones E, Sinclair JM, Holt RI, Barnard KD. Social networking and understanding alcohol-associated risk for people with type 1 diabetes: friend or foe? Diabetes Technology \& Therapeutics. 2013; 15(4):308-14

[9] Williams SA, Terras MM, Warwick C. What do people study when they study Twitter? Classifying Twitter related academic papers. Journal of Documentation. 2013; 69(3):384-410.

[10] Snell N. If you are not online, you don't exist. (Web $\log$ post). Retrieved from http://thesnell.com/blog/2009/03/03/if-youre-notonline-you-dont-exist/. Accessed 25 December 2016.

[11] Boyd D. Why youth (heart) social network sites: the role of networked publics in teenage social life. MacArthur foundation series on digital learning-youth, identity, and digital media volume. 2007:119-42.

[12] Kaplan AM, Haenlein M. Users of the world, unite! the challenges and opportunities of social media. Business Horizons. 2010; 53(1):59-68.

[13] Brandtzæg PB, Lüders M, Skjetne JH. Too many Facebook "friends"? Content sharing and sociability versus the need for privacy in social network sites. International Journal of Human-Computer Interaction. 2010; 26(11-12):1006-30.

[14] Wellman B. Structural analysis: from method and metaphor to theory and substance. Contemporary Studies in Sociology. 1997; 15:19-61.

[15] https://www.statista.com/statistics/278414/number-ofworldwide-social-network-users/ Accessed 25 August 2017.

[16] Błachnio A, Przepiórka A, Rudnicka P. Psychological determinants of using Facebook: a research review. International Journal of Human-Computer Interaction. 2013; 29(11):775-87.

[17] Caers R, De Feyter T, De Couck M, Stough T, Vigna $\mathrm{C}$, Du Bois C. Facebook: a literature review. New Media \& Society. 2013; 15(6):982-1002.

[18] Hew KF. Students' and teachers' use of Facebook. Computers in Human Behavior. 2011; 27(2):662-76.

[19] Manca S, Ranieri M. Is it a tool suitable for learning? A critical review of the literature on Facebook as a technology-enhanced learning environment. Journal of Computer Assisted Learning. 2013; 29(6):487-504.

[20] Nadkarni A, Hofmann SG. Why do people use Facebook?. Personality and Individual Differences. 2012; 52(3):243-9.

[21] Wilson RE, Gosling SD, Graham LT. A review of Facebook research in the social sciences. Perspectives on Psychological Science. 2012; 7(3):203-20.

[22] Dhir A, Buragga K, Boreqqah AA. Tweeters on campus: twitter a learning tool in classroom?. Journal of Universal Computer Science. 2013; 19(5):672-91.

[23] Snelson C. YouTube across the disciplines: a review of the literature. MERLOT Journal of Online Learning and Teaching. 2011; 7(1):159-69.
[24] Leung D, Law R, Van Hoof H, Buhalis D. Social media in tourism and hospitality: a literature review. Journal of Travel \& Tourism Marketing. 2013; 30(12):3-22.

[25] Kalampokis E, Tambouris E, Tarabanis K. Understanding the predictive power of social media. Internet Research. 2013; 23(5):544-59.

[26] Gross R, Acquisti A. Information revelation and privacy in online social networks. In proceedings of the ACM workshop on privacy in the electronic society 2005 (pp. 71-80). ACM.

[27] Fogel J, Nehmad E. Internet social network communities: risk taking, trust, and privacy concerns. Computers in Human Behavior. 2009; 25(1):153-60.

[28] Cecere G, Le Guel F, Soulié N. Perceived internet privacy concerns on social networks in Europe. Technological Forecasting and Social Change. 2015; 96:277-87.

[29] Yoo SJ, Huang WH. Comparison of web 2.0 technology acceptance level based on cultural differences. Journal of Educational Technology \& Society. 2011; 14(4):241-52.

[30] Tambouris E, Panopoulou E, Tarabanis K, Ryberg T, Buus L, Peristeras V, et al. Enabling problem based learning through web 2.0 technologies: PBL 2.0. Journal of Educational Technology \& Society. 2012; 15(4):238-51.

[31] Zdravkova K, Ivanović M, Putnik Z. Experience of integrating web 2.0 technologies. Educational Technology Research and Development. 2012; 60(2):361-81.

[32] Creswell J W. Research design: qualitative, quantitative, and mixed methods approaches. SAGE Publications, Incorporated; 2009.

[33] De Vaus DA, De Vaus D. Research design in social research. SAGE Publications; 2001.

[34] Johnson RB, Onwuegbuzie AJ. Mixed methods research: a research paradigm whose time has come. Educational Researcher. 2004; 33(7):14-26.

[35] Abbas T, Charles T. Handbook of mixed methods in social \& behavioral research. SAGE Publications; 2003.

[36] Danah b. Viewing American class divisions through Facebook and MySpace. http://www.danah.org/papers/essays/ClassDivisions.ht ml. Accessed 26 November 2017.

[37] Thelwall M. Social networks, gender, and friending: an analysis of MySpace member profiles. Journal of the Association for Information Science and Technology. 2008; 59(8):1321-30.

[38] Arnold SE. http://www.arnoldit.com/articles/saswhite-paper.pdf. Accessed 26 November 2017.

[39] Abrahams AS, Jiao J, Wang GA, Fan W. Vehicle defect discovery from social media. Decision Support Systems. 2012; 54(1):87-97.

[40] Lane PC, Clarke D, Hender P. On developing robust models for favourability analysis: model choice, feature sets and imbalanced data. Decision Support Systems. 2012; 53(4):712-8. 
[41] Harden A, Thomas J. Mixed methods and systematic reviews: examples and emerging issues. SAGE Publication. 2010.

[42] Schreier M. Qualitative content analysis in practice. Sage Publications; 2012.

[43] Golbeck J. Benford's law applies to online social networks. PlOS One. 2015; 10(8):e0135169.

[44] Mathers N, Fox NJ, Hunn A. Surveys and questionnaires. NHS Executive; 1998.

[45] Wright KB. Researching internet-based populations: advantages and disadvantages of online survey research, online questionnaire authoring software packages, and web survey services. Journal of Computer-Mediated Communication. 2005; 10(3).

[46] Thompson G. Between hierarchies and markets: the logic and limits of network forms of organization. Oxford University Press on Demand; 2003.

[47] Domínguez S, Hollstein B. Mixed methods social networks research: design and applications. Cambridge University Press; 2014.

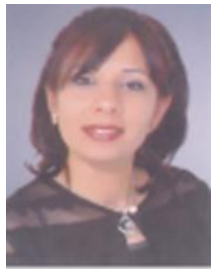

Ms. Heba Sayed is enrolled in a $\mathrm{PhD}$ at School of Science and Technology at MiddleSex University, United Kingdom. She holds a Master in Business Information Technology from MiddleSex University in 2003 and a BA in Business Administration from The American University in Cairo (AUC) in 1998. She has consulted Arab regional governments and corporations addressing organizational transformation, executive development, management and ICT Strategy. Her work is published in IS and management journals and presented at ECIS, Utrecht, The Netherlands conference. She is a co-editor of "Cases on Web 2.0 in Developing Countries: Studies on Implementation, Application and Use" book. Email: ha156@live.mdx.ac.uk. 